\title{
SENSORIAL ANALYSIS OF LOWER THORACIC ERECTOR SPINAE PLANE BLOCK; MISSING PIECE IN THE PUZZLE
}

\section{S. Tulgar， $\underline{0 . \text { Selvi }}$}

Maltepe University Faculty of Medicine, Anesthesiology and Reanimation, Istanbul, Turkey.

\section{Background and Aims:}

- The Erector spinae plane block (ESPB) is a new interfascial plane block.

- Most of the studies have evaluated ESPB applied at upper thoracic region.

-We aimed to investigate sensory block in different compartments in the thoraco-abdominal region in patients who underwent bilateral ESPB from thoracic (Th) 9 level.

\section{Methods:}

-The study was started in November 2018 (NCT03744520).

\section{- Written informed consent was obtained} from all patients for procedures, dermatome analysis and publishing.

- Bilateral ESPB with $30 \mathrm{~mL} 0.25 \%$ bupivacaine was applied in abdominal surgery patients and sensory analysis was performed with pinprick test 3 hours after block application.

-Each dermatome was evaluated separately and divided into fourquadrants: dorsomedialdorsolateral, ventral-lateral and ventromedial, from the posteromedial to the front.

\section{Results:}

-A total of 25 patients underwent 50 ESPBs.

\section{- 3 blocks were evaluated as sensory} failure in all four quadrants. Dorsomedially 10, dorsolaterally 13, ventral-laterally 6 and ventralmedially 15 blocks were accepted as failed block.

-The sensory features of the blocks are shown in Only half of the applications were able to block 4 quadrants between Th7-Th10 (Figure 1).

- There was a significant difference between the right and left block distributions (IRR < 0.30).

\section{The Erector spinae plane block (ESPB) applied at T9 levelshows different block characteristics in varying dorsal and ventral quadrants. The success of sensory block in the mid-abdominal and parasternal regions are relatively low.}

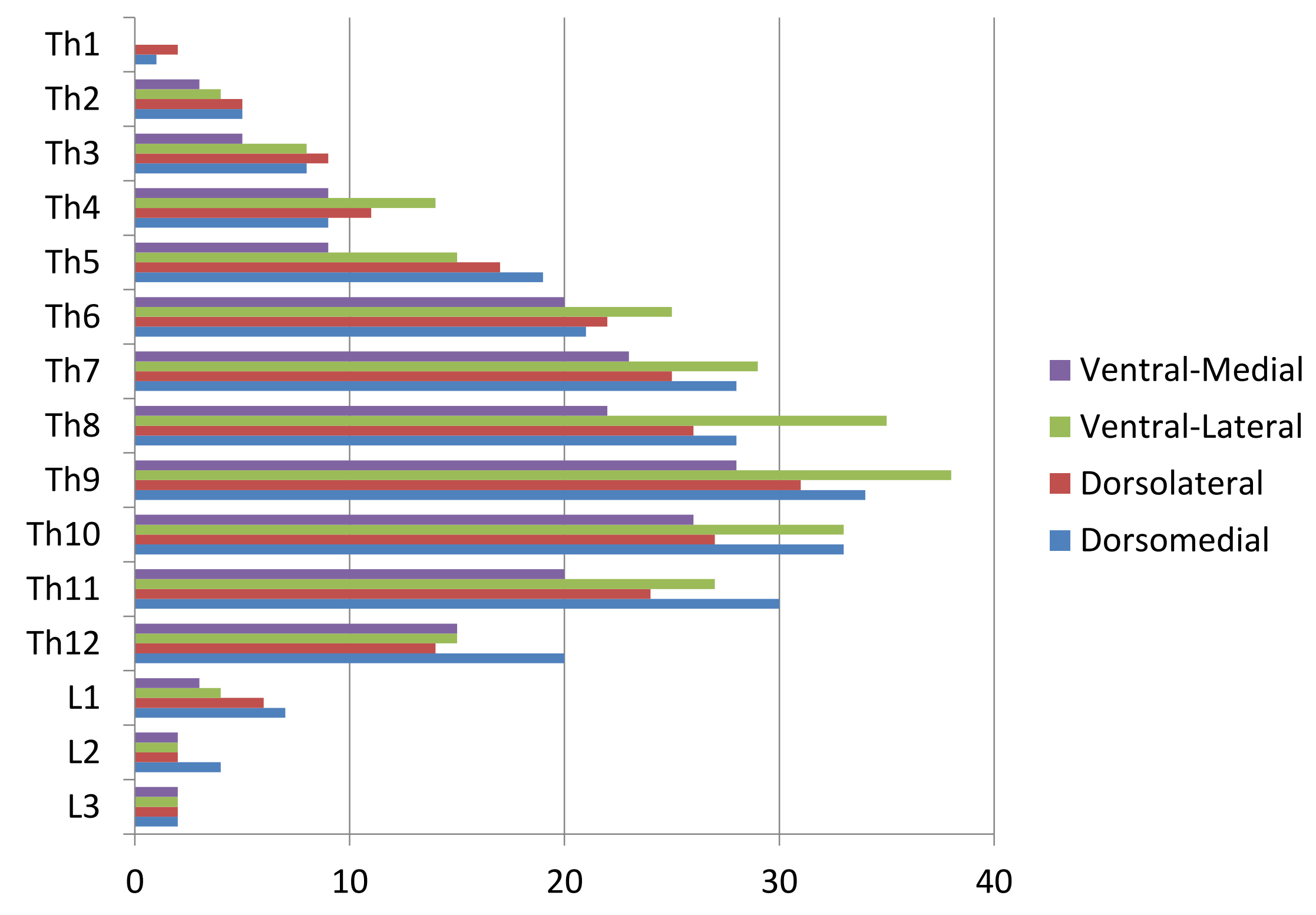

References: 1 . Schwartzmann A, Peng P, Maciel MA, Forero M. Mechanism of the erector spinae plane block: insights from a magnetic resonance imaging study. Can J Anaesth [Internet]. 2018 Aug 3; Available from: http://dx.doi.org/10.1007/s12630-018-1187-y 2. De Cassai A, Bonvicini D, Correale C, Sandei L, Tulgar S, Tonetti T. Erector spinae plane block: a systematic qualitative review. Minerva Anestesiol [Internet]. 2019 Jan 4; Available from: http://dx.doi.org/10.23736/S0375-9393.18.13341-4

Contact info: Dr. Onur Selvi prostel@yahoo.com Tel: +905337799760 